\title{
Religious Belief, Scientific Expertise, and Folk Ecology*
}

\author{
Devereaux A. Poling** and E. Margaret Evans***
}

\begin{abstract}
In the United States, lay-adults with a range of educational backgrounds often conceptualize species change within a non-Darwinian adaptationist framework, or reject such ideas altogether, opting instead for creationist accounts in which species are viewed as immutable. In this study, such findings were investigated further by examining the relationship between religious belief, scientific expertise, and ecological reasoning in 132 college-educated adults from 6 religious backgrounds in a Midwestern city. Fundamentalist and non-fundamentalist religious beliefs were differentially related to concepts of evolution, adaptation, and extinction. Biological expertise $(r=.28)$ and creationism $(r=-.46)$ were significantly and differentially related to the endorsement of the Darwinian concept of common descent. Yet, creationists were more likely to reject macroevolutionary than microevolutionary concepts. Overall, the greater the taxonomic distance between species, the less likely were participants to agree that species-pairs had common ancestors. It is argued that lay adults from contemporary industrialized societies adopt a view of evolution in which species adapt to novel environments, but remain the same "kind" despite changes. Therefore, extinction is considered unlikely and the relations between micro- and macroevolution misconstrued. Lay-adults' species concepts appear to be an amalgam of a common-sense understanding of species and of evolutionary ideas, modified but not transformed by religious and scientific beliefs. Finally, it is argued that the development of scientific expertise does not involve the radical transformation of ingrained worldviews. Rather, scientists select specializations that are compatible with their existing philosophies, then consciously apply the constructs of their disciplines in order to transcend their common-sense folk beliefs.
\end{abstract}

*An earlier version of this study was presented at the $14^{\text {th }}$ Annual Convention of the American Psychological Society in New Orleans, LA, June 2002. We wish to thank Peg Hull Smith, Steve Christman, Wallace E. Dixon Jr., and Jean Funk for earlier comments on this study, and, in particular, thank Neeraj Gonela for helping to construct the items and for data collection. A special thanks to undergraduate students and members of the community who completed these questionnaires.

** Department of Psychology, Ohio University. Correspondence concerning this article should be addressed to Devereaux A. Poling, Asst. Professor of Psychology, Ohio University-Zanesville, 1425 Newark Rd., Zanesville OH 43701.

*** Center for Human Growth and Development, University of Michigan. 


\section{Introduction}

Shortly after Alfred H. Meyer (1893-1988) submitted his doctoral dissertation on geology, he abandoned the "heretical" topic altogether and subsequently specialized in a theologically less suspect field, that of land utilization (Numbers 1992). It was not Meyer's scientific expertise that was at issue, but the challenge that historical geology offered to his strongly held beliefs in the inerrancy of the biblical account of the creation, in which God created each species individually, a few thousand years ago. Similar "spiritual anguish" (Numbers 1992, p. 274) was voiced by urban lay adults, when asked to what extent they endorsed creationist or evolutionist accounts of the origins of species: "I don't know what to believe, I just want my kids to go to heaven" (Evans 2001, p. 261).

For researchers interested in the interplay between cultural beliefs, folk beliefs, and science, the clash between Darwinian evolution and strict creationism provides a fascinating entrée into this topic, as these examples demonstrate. Moreover, investigations of this controversy have implications that go well beyond the light they can shed on basic cognitive and cultural processes and the nature of scientific thinking. Almost half of the American public endorses some form of creationist belief, as do many of its political leaders (e.g., Pennock 2002). Given that evolutionary theory plays such a central role in modern science, this widespread resistance has a potentially large impact on a range of U.S. public policies. If a sizable minority of the lay public and political leadership reject the scientific reasoning underlying topics from species extinction to genetics, they cannot make informed policy decisions on such topics. There are few studies of the impact of religious belief on the folk ecology of the urban lay-adult (or child), despite its intrinsic value and policy implications. We begin to fill this gap by examining the ecological reasoning, in particular the species concepts, of a sample of U.S. Midwestern college-educated adults. The core question addressed is to what extent do science and religion impact urban adults' commonsense or folk understanding of the natural world? Later, we discuss the implications of our findings for the practice of science itself.

Commonsense reasoning refers to the kind of everyday explanations that most easily come to mind when humans solve problems. Such reasoning regularly defies researchers' efforts to induce abstract reasoning strategies such as propositional logic or probabilistic reasoning in their 
subjects (e.g., Johnson-Laird, Legrenzi \& Girotto 2004; Tversky \& Kahneman 1974). More specifically, a focus on the domain of folk biology reveals the means by which humans ordinarily reason about and classify nature. From a series of studies of the folk biological concepts of diverse populations, Scott Atran, Douglas Medin, and their colleagues concluded that in comparison with that of North American naturalists and Mayans of all backgrounds, North American undergraduates' knowledge of nature is relatively impoverished (see Atran, Medin \& Ross 2004; Medin \& Atran in press). Further, they argue that urban undergraduates' limited exposure to the natural world often forces them to rely on similarity heuristics and other domain-general reasoning strategies. In spite of these differences, however, all the populations they sampled, like those in many traditional cultures, privileged the generic-species rank (dog) over the lifeform (mammal), kingdom (animal), or folk specific (terrier) ranks when reasoning about animal properties and behaviors (Atran, Medin \& Ross 2004; Medin \& Atran 2004). Anthropologists have long claimed that the generic-species level comprises the most perceptually salient features of the natural environment, forming the building block for folk taxonomies in cultures the world over (see Atran, Medin \& Ross 2004).

In this study, we ask urban North American adults to extend their commonsense understanding of the natural world to address questions of species origins and extinction, which not only arouse existential concerns (Evans, Poling \& Mull 2001; Poling \& Evans 2004) but for which the evidence is not immediately apparent. Cultural differences are more likely to surface in the face of such uncertainty (Atran 1998). We use the terms folk ecology and folk biology interchangeably, with an emphasis on the folk understanding of animals as adaptive organisms.

There are many reasons to suspect that folk concepts of species are resistant to the arguments of modern evolutionary theory. We summarize those findings, before describing the effects of creationist belief. The profound metaphysical doubts expressed by creation scientists or creationist lay-adults when confronting evolutionary arguments, are poignantly illustrated in the examples presented earlier. But the presence of such existential concerns does not mean that creationism has necessarily impacted their folk ecology. It should be emphasized that most contemporary religions endorse some form of theistic evolution, in which the tenets of Darwinian 
evolution are accepted, but God is considered to be the final cause. This compromise is explicitly rejected by Biblical literalists (Evans 2000b; Numbers 1992). First, we describe the relationship between folk concepts of species and evolutionary theory. Then, we turn briefly to creationism and examine its relationship to folk beliefs.

Historically, a variety of pre-Darwinian ideas regarding evolutionary change have existed (Chambers 1994). Central to all of these ideas was the concept of species change and the notion that natural rather than divine law might explain species origins (Secord 1994). In contemporary urban populations, most research on concepts of evolution has been carried out in a specific framework, that of science educators concerned with the alternative conceptions that students bring to the classroom (Evans \& Rosengren 2004). From Deadman and Kelly's (1978) study of British students' preinstructional concepts onwards, researchers have consistently found that students' intuitive ideas of species change include: a needbased concept of species adaptation, a belief in the inheritance of acquired characteristics, and a limited understanding of species variation, chance, or probability (e.g., Clough \& Wood-Robinson 1985; Ferrari \& Chi 1998; Settlage, Jr. 1994). Studies in different languages and cultures reveal a similar set of concepts (e.g., Banet \& Ayuso 2003; Dagher \& BouJaoude 1997; Hatano, Inagaki \& Morita 2002). For example, Bizzo (1994) found that Brazilian high-school students' conceptualize evolution as growth and improvement. Even Ivy-League undergraduates endorse these ideas (Shtulman 2003). Although students invoke natural rather than divine law, their intuitive biological concepts are clearly at odds with Darwinian themes of random variation and selection.

Subsequent studies found that students' intuitive concepts of species change are resistant to even the most targeted instruction aimed at imparting Darwinian theory (e.g., Bishop \& Anderson 1990; Brumby 1979, 1984). To explain this resistance, researchers examined a number of factors, most of which had limited effects, from the delivery of evolutionary concepts in textbooks and in the classroom, to student characteristics, such as their reasoning ability and worldviews (e.g., Anderson, Randle \& Covotsos 2001; Jeffrey \& Roach 1994; Lawson \& Worsnop 1992; Swarts, Anderson \& Swetz 1994; Trowbridge \& Wandersee 1994). Students' worldviews (e.g., Cobern 2000), especially their religious beliefs, do impact 
their attitudes, in that they often view evolution negatively (e.g., Brem, Ranney \& Schindel 2003; Evans 2000b). But, we shall argue, such views are more likely to impact students' resistance to macroevolutionary than microevolutionary concepts. Most studies on students' concepts target microevolutionary processes. A recent, potentially more promising focus has been on students' understanding of the nature of science (e.g., Bell, Lederman \& Abd-El-Khalick 2000) and the nature of knowledge (e.g., Sinatra, Southerland, McConaughy \& Demastes 2003). Interventions that target both students' naive epistemology and their intuitive biology appear to be more successful in effecting conceptual change in the classroom (e.g., Passmore \& Stewart 2002; Sandoval \& Morrison 2003).

Missing from this extensive literature is a conceptual framework in which such findings can be interpreted: When do such intuitive ideas first emerge? Why do they persist? Evans and Rosengren (2004) advocate a developmental approach that goes beyond the well-established body of work on preinstructional conceptions in which isolated components of a student's prior knowledge are thought to constrain the acquisition of new knowledge (e.g., Wandersee, Mintzes \& Arnaudin 1987). Concepts of species change, it is hypothesized, are strongly rooted in intuitive ontologies, where species are essentialized and creation and change are controlled by design, not subject to random natural processes (Evans \& Rosengren 2004; see also, Atran 1990; Evans 2001; Mayr 1982). Such ontological constraints can inhibit or facilitate the acquisition of the novel knowledge structures that underlie Darwinian evolutionary concepts. The goal of a developmental approach is to specify the state of the initial causal principles and describe how they are transformed with the appropriation of new knowledge (Keil \& Wilson 2000; Poling \& Evans 2002; Vosniadou \& Ioannides 1998). Next, we describe the emergence of these concepts in children whose demographic characteristics are similar to those of the lay-adults in the current study.

Although there is considerable controversy regarding the nature and development of children's reasoning (e.g., Atran 1995; Carey 1995; Inagaki \& Hatano 2002; Keil 1994; Wellman \& Gelman 1998), recent research indicates that three modes of construal, essentialism, teleology, and intention, constrain children's and adults explanations of living kind behaviors (Carey 1985; Keil 1994; Southerland, Abrams, Cummins \& Anzelmo 
2001). Psychological essentialism (Medin \& Ortony 1989) captures the notion that individuals reason as if entities have a unique nature that stems from some underlying and unobservable causal essence (Gelman 2003). The concept of an essence placeholder has been utilized to explain children's and adults' reasoning about natural and social categories (Gelman 2003; Medin \& Ortony 1989). Such reasoning likely gives rise to a view of species as stable and unvarying and significantly undermines attempts to convey a Darwinian perspective, in which species are not only seen as variable, but subject to dramatic change (Mayr 1982). Biblical literalists hyper-essentialize species, expressing an explicit belief in the immutable God-given essence of natural kinds (Evans 2001). Young children's essentialist thinking, in contrast, seems relatively inchoate, predicated on an unanalyzed internal cause or innate potential (Gelman \& Wellman 1991). Even so, preschoolers apparently endorse a core essentialist notion that an animal's appearance changes little with development, though in the school-age years children accept a range of within-species changes, including metamorphosis (Rosengren, Dehart, Taylor \& Marzolf 2003; Rosengren, Gelman, Kalish \& McCormick 1991). By the end of the elementary school years children express concepts of need-based adaptive change, unless they have been inculcated with creationist beliefs (Evans 2000a, 2001; Samarapungavan \& Wiers 1997).

In addition to essentialist beliefs in the stability of species, teleological beliefs also act as a barrier to Darwinian evolutionary theory. Teleological beliefs seem central to a commonsense understanding of biology, probably because living organisms appear to act in a goal-directed purposeful manner (Allen, Bekoff \& Lauder 1998; Opfer 2002). Keil (1994) distinguishes between functions that serve the needs of the entity in question (e.g., eyes for seeing) and those that are other-directed (see also, Kelemen 1999). The latter are characteristic of artifacts, such as chairs, which serve the needs of a human creator. Importantly, purposive behavior is, in principle, separable from intentionality (Keil 1994). Although the behavior of insect collectives, such as ant colonies, appears to be goal-directed, it is better described as teleo-essentialist (Atran 1990), with the behavior linked to genes, not intention. A focus on adaptive variation within species (microevolution) rather than on the origin of new species appears to elicit non-intentional but teleological or need-based reasoning in children and Biblical literalists, 
alike (e.g., Evans 2000a; 2001; Samarapungavan \& Weirs 1997; Southerland et al. 2001).

Questions on macroevolution, however, which explicitly address the origins of new species (the very first), are more likely to elicit the "argument by design" (Dawkins 1987). In this case, species are treated as the intentional artifacts of a superhuman creator. For example, in contrast to younger and older children, 8- to 10-year-olds from Christian Fundamentalist and matched non-fundamentalist school communities appeared to be almost exclusively creationist (God made it) regardless, of parental or community beliefs (Evans 2001). The beliefs of 10- to 12-year-olds, though, mirrored community norms: evolutionist or creationist. Evans argued that young children generate intuitive causal explanations about origins, both intentional and naturalistic, whereas communities privilege certain beliefs and inhibit others, thus engendering uniform cultural belief systems. Tento twelve-year-olds acceptance of macroevolution was related to three key factors, independently of age and of each other (together explaining 70\% of the variance): (1) the coherence of parental beliefs, (2) knowledge of the fossil evidence, and (3) endorsement of the inheritance of acquired traits (e.g., giraffes' long necks result from their habit of stretching into tall trees to feed; their offspring inherit this characteristic). Older children from Christian fundamentalist schools were more likely to resist such ideas, by responding, for example, "God made it that way, so it can't change" (Evans 2001).

It is argued that the creationist-to-evolutionist shift seen in the 8- to 12-year-olds from non-fundamentalist communities, represents a shift from a preference for teleo-intentional causes (God's purpose) to a preference for teleological or teleo-essentialist causes (Evans 2001). In the first case, the origin of species is linked to a supernatural cause, but in the latter cases, it is linked to a naturalistic cause. Experimental evidence confirms that when reasoning about the diverse behaviors of humans and other species, 6- to 12-year-olds and adults demonstrate causal flexibility, the ability to shift explanations depending on the available evidence and the particular context (Gutheil, Vera \& Keil 1998; Poling \& Evans 2002). In Poling and Evans' studies, an age-related shift in explanation preference was apparent, from teleo-intentional to teleo-essentialist, which seemed to reflect changes in default biases, from intentionality to essentialism. Superficially, these 
findings would appear to bolster the position (Carey 1985) that children initially reason about the biological world from a psychological perspective.

Despite their apparent preference for intentional arguments, however, the youngest children in the Poling and Evans studies were as likely as adults to apply teleological explanations to the behaviors of prototypical animals, ungulates, and to prototypical biological processes, such as breathing (2002). Such an early sensitivity to functional explanations highlights the crucial role that teleology plays in an intuitive biology, even when knowledge of causal mechanisms is limited (see also, Inagaki \& Hatano 2002; Kelemen 1999, 2004; Opfer 2002; Springer \& Keil 1989). Moreover, this result provides evidence for the most recent consensus on the developmental trajectory (e.g., Carey 1985, 1995; Poling \& Evans 2002; Medin and Atran in press), which is that children are anthropocentric to the extent that they lack core biological knowledge. North American urban children, like the undergraduates described earlier, are more likely than rural or Native American children to experience biologically impoverished natural environments and are more likely to be anthropocentric (Ross, Medin, Coley \& Atran 2003). Creationist children in Evans' (2001) study were less likely than evolutionists to know about fossils and adaptation. Yet, additional factors clearly played a role. The community emphasis on God's purpose in the creation story rendered children from Christian fundamentalist schools resistant to any evidence from nature that animals might change. Interestingly, Christian fundamentalist parents were significantly less likely than non-fundamentalist parents to encourage their children's interest in nature and significantly more likely to emphasize religion (Evans 2001).

Although to the evolutionary biologist macro- and micro-evolution are seamless processes, these findings suggest that it is not necessarily the case for the layperson. The historical and contemporary evidence indicates that macro- and microevolutionary constructs are subject to different developmental constraints (Evans \& Rosengren 2004). Creation scientists claim that they accept adaptive variation (microevolution), which explains phenotypic variation and is built into the species essence - presumably by God (Evans 2001; Morris \& Parker 1982). Any suggestion that new species originated from earlier forms (macroevolution), however, provokes outrage (Crews 2001) and has been dubbed atheistic evolution or a naturalistic religion (Pennock 2002). Creation scientists justify this distinction by noting 
that adaptive variation in species can be observed, whereas the evidence for macroevolution is inferred (Chick 2000).

Without a clear concept of species (Mishler 1999), however, any relationship between adaptive variation and speciation seems moot (Evans \& Rosengren 2004). For a pre-Darwinian, the term "species" referred to kinds produced by Biblical creation (Mayr 1982). Mayr (1991) further claimed that pre-Darwinians viewed species as immutable with unchanging essences. Atran (1990) argued, instead, that even prior to Darwinism, natural historians, at least, rarely applied a strict view of essentialism. An influential post-Darwinian view of species, developed by Mayr (1982), is of a geographically isolated, interbreeding, natural population. Thus, from the expert perspective, species are temporary spatio-temporal constructs with permeable boundaries (Atran 1990). From the common-sense perspective of the traditional folk theorist, visible species appear to occupy distinct ecological niches and have fixed boundaries (Atran 1990), a contrast to the expert view. To fully grasp macroevolutionary concepts, a post-Darwinian concept of species seems necessary. Overall, this evidence indicates that of the two constructs, macroevolution is the more counterintuitive. Although essentialist constraints can be modified to accept microevolutionary processes, such as adaptive variation, essentialist constraints have to be radically transformed to endorse macroevolution. If each species is considered to have a unique essence, macroevolutionary change, in which one species can be considered the ancestor of a later emerging form, is especially problematic (Evans \& Rosengren 2004). Adaptive variation without speciation, on the other hand, appears to map easily onto the preinstructional or folk concepts of need-based within-species change. Evolutionary biologists, though, may retain the psychological notion of essence when they reference common ancestral lines in terms of shared genetic structures (Atran 1998; Evans 2001).

The accumulated evidence suggests that essentialism, teleology, and intention are all used to explain species and species change, with specific combinations of these causal principles delivering particular kinds of explanations (e.g., see Keil \& Wilson 2000). Moreover, participants can potentially shift between explanatory modes, depending on the available evidence. Such causal flexibility is necessary to explain cultural and historical shifts in reasoning as individuals assimilate cultural knowledge. We summa- 
rize our position in Figure 1, in which we note the concepts of species and species change held by creation scientists, folk biologists, and evolutionary biologists (Evans \& Rosengren 2004). Evolutionary biologists, we argue, explicitly link teleology and essentialism, in terms of genetic structures that represent adaptation to past environments. On the other hand, Creation Scientists hyper-essentialize species in terms of God's intended purpose. In this paper, we examine whether individuals' everyday reasoning about species and species change is modified or transformed when they are exposed to competing cultural models: creationism and Darwinian evolution. The findings are used to address several key questions: What is the nature of a folk ecology? What is the effect of religion and science on that folk ecology? To what extent are evolutionary biologists or creation scientists constrained by their commonsense understanding of the natural world?

In the following study, we examined the species concepts of urban lay adults from different religious backgrounds, using open-ended and closed-ended questions. We assessed the extent to which participants recognized that species share a common ancestry and are responsive to environmental change, and then related this recognition to a variety of constructs, including participants' religiosity, creationist beliefs, and completed biology classes. In the first set of analyses we used self-reported religious affiliation as a grouping variable, with the other variables as dependent measures. This was followed by analyses of the strength of the relationship between variables. We expected that religious groups would differ in their acceptance of biblical inerrancy, with Christian fundamentalists more likely to endorse the biblical view of the creation (Doyle 2003). According to Doyle, though, individuals from other religious groups are often creationist, with about $30 \%$ of U.S adults accepting biblical inerrancy ("The Bible is the actual word of God and is to be taken literally"). Therefore, in the second set of analyses we utilized a creationist construct that reflected this variation and disregarded religious affiliation. In a final set of analyses, we evaluated whether participants who accepted or rejected creationism endorsed teleological, intentional, selectional, or theistic modes of species change or utilized diversity reasoning.

Adolescents and young adults appear to endorse a folk ecology that incorporates within-species variation, insofar as it results from developmental change, growth or a heritable need-based adaptation to changed environ- 


\begin{tabular}{|c|c|c|c|}
\hline & $\begin{array}{l}\text { CREATION } \\
\text { SCIENTIST }\end{array}$ & FOLK BIOLOGIST & $\begin{array}{l}\text { EVOLUTIONARY } \\
\text { BIOLOGIST }\end{array}$ \\
\hline SPECIES CONCEPT & $\begin{array}{l}\text { Rule-Based: Fixed, } \\
\text { hyper-essentialized } \\
\text { groups created } \\
\text { individually by God }\end{array}$ & $\begin{array}{l}\text { Commonsense: } \\
\text { Visible generic- } \\
\text { species; adaptive, } \\
\text { need-based change }\end{array}$ & $\begin{array}{l}\text { Rule-Based: } \\
\text { Temporary, } \\
\text { reproductively } \\
\text { isolated groups }\end{array}$ \\
\hline $\begin{array}{l}\text { EVOLUTIONARY } \\
\text { CONCEPT }\end{array}$ & $\begin{array}{l}\text { Microevolution } \\
\text { (adaptive variation } \\
\text { within species) }\end{array}$ & Microevolution & $\begin{array}{l}\text { Macro- and } \\
\text { Microevolution }\end{array}$ \\
\hline $\begin{array}{l}\text { SPECIES } \\
\text { EXTINCTION }\end{array}$ & No & Perhaps & Yes (central concept) \\
\hline $\begin{array}{l}\text { CAUSAL } \\
\text { CONSTRUCT }\end{array}$ & & & \\
\hline $\begin{array}{r}\text { ESSENTIALISM } \\
\text { TELEOLOGY } \\
\text { (GOD'S) INTENTION }\end{array}$ & $\begin{array}{l}+ \text { linked } \\
+ \text { linked } \\
+ \text { linked by God }\end{array}$ & $\begin{array}{l}+ \\
+ \\
-\end{array}$ & $\begin{array}{l}\text { + linked } \\
+ \text { linked by genes } \\
\text { - }\end{array}$ \\
\hline
\end{tabular}

Figure 1. A summary of creation scientists', folk biologists', and evolutionary biologists' concepts of species and species change (adapted from Evans \& Rosengren 2004).

ments. The nature of their species concepts is unclear. We hypothesize that in a lay population, at least, exposure to Darwinian or creationist cultural models will result in a modification rather than a radical transformation of these and related concepts. Specifically, creationists will be more likely to endorse an essentialist belief in the immutability of species and reject extinction and macroevolutionary change, whereas evolutionists will be more likely to endorse concepts of species variability, change, and extinction, the interconnectedness of species (Poling \& Evans 2003; Ross, Medin, Coley \& Atran 2003), and common descent (see Figure 1).

\section{Method}

\section{Participants}

Participants were 111 adults ranging in age from 18 to 30 years (26 male, 85 female). The majority of them were White $(n=83)$; of the rest: African American $(n=11)$, Asian/Pacific Islander $(n=3)$, Multi-ethnic $(n=1)$ and other $(n=13)$. On the basis of self-report, participants were sep- 
arated into six religious groups: Christian Fundamentalist $(n=21$, e.g., born-again Christian, Baptist), Christian Non-Fundamentalist $(n=22$, e.g., Methodist, Presbyterian), Catholic $(n=31$, e.g., Catholic, Roman Catholic), Islamic $(n=13)$, Agnostic/None $(n=17)$, Other $(n=6$, e.g., Pagan, Wicca). ${ }^{1}$ Participants were recruited through university international organizations, and psychology classes, and gave written consent prior to participation.

Demographics: Age, Education Level, Biology Classes. Religious groups did not differ significantly on age, educational level, or the number of completed biology classes. Age-range was measured on the following scale: $1=18-24$ years, $2=25-30$ years, $3=31-35$ years, $4=36-40$ years, $5=41-45$ years, $6=46-50$ years, $7=51-55$ years, $8=56-60$ years, $9=61+$ years. Mean age for all groups ranged from 1-1.55 (SDs 0-0.52), which corresponds to 18-24 years. Educational level was measured on the following continuum: $1=$ high school completion, $2=$ some college, $3=2$-year college, $4=4$ year college completion $5=$ some graduate school. Mean education levels for all groups ranged from 2.1 to 2.67 (SDS 0.89 to 1.2). All groups had a range from 1-5. Finally, the mean number of biology classes completed ranged from 0.60-1.9 (SDs 0.54-2.2). All groups had a range from 0-10 classes (except for the "Other" group: Range 0-1).

\section{Materials and Procedure}

A three-part questionnaire was administered to each participant. Participants were informed that the questionnaire focused on the relationship between religion, educational expertise, and species related beliefs. The first section consisted of 85 randomly ordered items to which participants rated their level of agreement. These items were then used to create the seven major constructs discussed below. In the second section, participants read brief scenarios on environmental change and responded to a series of questions about adaptation (see Appendix A for scenarios). In the final section, participants provided demographic information, including religious

\footnotetext{
${ }^{1}$ Originally, a seventh religious group participated, consisting of Hindus $(n=21)$ recruited from a local Hindu temple. They were subsequently excluded from the analyses because of significant differences between them and the other religious groups on age, education level and biological expertise.
} 
affiliation and educational background, and responded to a series of openended questions, probing their species concepts. Participants filled out the questionnaire in various settings, such as classrooms, the student union, the library, and in their own home settings.

\section{Scoring}

Most items were scaled on a five-point Likert scale $(1=$ strongly disagree; $2=$ disagree, $3=$ neither agree nor disagree, $4=$ agree, $5=$ strongly agree). Thus, each question yielded a score ranging from 1-5 with 5 (strongly agree) representing a strong endorsement of the item. In the small percentage of items that were reverse coded, high scores indicated strong disagreement.

\section{Results}

Results will be reported in four sections. First, we describe the openended items and report those responses. This is followed by a description of the major constructs and the relationships between those measures, the religious affiliation, and the beliefs of the participants. In the final sections, participants' responses to the adaptation scenarios will be related to their agreement with two of the major constructs, creationism and common descent. Finally, we report the relationship between creationism and diversity reasoning.

\section{Open-Ended Questions}

Two independent raters, blind to the hypotheses of the study, coded responses from three open-ended questions probing participants' concepts of species and extinction. For each question, rater reliability was calculated using Cohen's kappa (Cohen 1960). In this section, the coding schemes for each of these three questions will be described and the percentage of participants who gave each type of answer will be reported. Analyses of variance (ANOVAs) on religious groups revealed no significant differences in responses to any of the items. Therefore, all percentages reported below will be collapsed across religious groups. 
Table 1

North American Urban Adults' Definitions of Extinction

\begin{tabular}{lc}
\hline Response Categories & \% Total Responses \\
\hline Death or disappearance without reference to species (e.g., "something & 13 \\
is gone and will never be seen again") & 13 \\
$\begin{array}{l}\text { Death or disappearance of a group or category (e.g., "group ceases } \\
\text { to exist") }\end{array}$ & 69 \\
$\begin{array}{l}\text { Death or dying out of a species (e.g., "When an entire species } \\
\text { dies out") }\end{array}$ & 5 \\
No answer & 5 \\
\hline
\end{tabular}

Question 1: In your own words, define extinction. (Cohen's kappa $=.81$ ). See Table 1. These findings suggest that the majority of participants in this study know that extinction refers to the death of a species. However, this result can only be interpreted within the context of these participants' concept of species.

Question 2: In your own words, define species. (Cohen's kappa $=.75)$. Webster's Encyclopedic Unabridged Dictionary of the English Language (1994) defines species as, "The major subdivision of a genus or subgenus, regarded as the basic category of biological classification, composed of related individuals that resemble one another, are able to breed among themselves, but are not able to breed with members of another species." The majority of participants characterized species as any group or category without mentioning reproduction or evolution (see Table 2).

Question 3: Will every single existing species someday be extinct? Why or why not? (Cohen's kappa $=.63$ ). This question was first coded for participants' responses of no, maybe and yes. Twenty-five percent of participants said no, $8 \%$ of participants said maybe, and $47 \%$ of participants said yes (19\% did not answer this question). Fifty-one percent of participants who responded to this question provided a reason (why or why not:') for their response (see Table 3).

Two key findings emerge from the open-ended questions. First, lay adults in this study appear to possess a pre-Darwinian concept of species, in that the majority of adults conceptualized species as groups of animals with a common "essence." Second, most lay adults express uncertainty or 


\section{Table 2}

North American Urban Adults' Definitions of Species

\begin{tabular}{lc}
\hline Response Categories & \% Total Responses \\
\hline $\begin{array}{l}\text { Group or category with no mention of reproduction or evolution } \\
\text { (e.g., "groups like mice or humans") }\end{array}$ & 59 \\
Anything living (e.g., "anything that exists") & 19 \\
$\begin{array}{l}\text { Any group created by God (e.g., "all living and nonliving things that } \\
\text { have been created by the almighty") }\end{array}$ & 5 \\
$\begin{array}{l}\text { Any group sharing a common ancestry (e.g., "similar characteristics } \\
\text { and adaptations between animals") }\end{array}$ & 5 \\
$\begin{array}{l}\text { Any group who reproduces with its own kind (e.g., "a group } \\
\text { of something that is reproductively isolated") }\end{array}$ & 2 \\
No answer / other & 9 \\
\hline
\end{tabular}

\section{Table 3}

North American Urban Adults' Reasons for Why Every Single Species Will (or Will Not) Become Extinct Someday

Response Categories

No: Every species will not become extinct

\% Total "No" Responses

Humans will escape (e.g., "No, humans will not become 11 extinct because they reproduce every day")

Death rates will not exceed birthrates (e.g., "No, the species will keep on dying but more will be brought about by reproduction")

Species will be able to adapt (e.g., "No - some species will be able to adapt to any environmental changes")

Did not provide a reason

Yes: Every species will become extinct \% Total "Yes" Responses

Environmental changes (e.g., "Yes - due to environmental 51 changes caused by man or nature")

By-product of the Day of Judgment (e.g., "Yes, when Jesus returns, every species will either go to heaven or hell and none will be left on earth")

Did not provide a reason

denial about the near-inevitability of extinction; further, of those that agree with extinction inevitability, only half provide a naturalistic cause. 


\section{Major Constructs \& Effects of Religious Group}

Questionnaire items were grouped into seven major constructs based both on prior theoretical constructs and on the psychometric properties of the items (each construct is described below). An average score was calculated across items. Each item was scaled on a five-point Likert scale: $1=$ strongly disagree; $2=$ disagree, $3=$ neither agree nor disagree, $4=$ agree, $5=$ strongly agree. Thirty-five items were excluded due to poor psychometric properties (e.g., ambiguous wording, failure to correlate with the other items) or because they were intended as filler items. Cronbach's alphas were used to determine the reliability of each of the major measures.

Means and standard deviations on all the major constructs by religious group can be seen in Table 4. A mixed design ANOVA (religious group $\mathrm{x}$ major construct), with major construct as the repeated measure variable revealed a significant main effect for construct, $F(6,630)=37.1$, $p<.0001$, and a construct by religious category interaction, $F(30,630)=$ $3.83, p<.0001$ (Greenhouse-Geisser corrections used). To explore the interaction, further analyses were computed using single factor ANOVAs for religious group on scores for each of the main constructs, in turn, and by Bonferroni post hoc comparisons where there was a significant effect (all $p_{\mathrm{s}}<.05$ ). Significant effects are reported below.

(1) Common Descent ( $\alpha=.87, M=3.27, S D=.69$ ). Eleven items were included in this measure, which focused on the Darwinian theory

\section{Table 4}

Means (and Standard Deviations) for Each Religious Group on Seven Major Constructs ${ }^{*}$

\begin{tabular}{lllllll}
\hline Construct & $\begin{array}{l}\text { Christian } \\
\text { Fund. }\end{array}$ & $\begin{array}{l}\text { Christian } \\
\text { Nonfund. }\end{array}$ & Catholic & Islam & $\begin{array}{c}\text { Agnostic/ } \\
\text { none }\end{array}$ & Other \\
\hline Common Descent & $2.97(.86)$ & $3.17(.49)$ & $3.57(.60)$ & $3.02(.7)$ & $3.34(.73)$ & $3.49(.51)$ \\
Creationism & $3.71(.76)$ & $3.22(.60)$ & $2.95(.54)$ & $3.26(.41)$ & $2.87(.90)$ & $3.06(1.3)$ \\
Adaptation & $3.12(.79)$ & $3.69(.42)$ & $3.71(.46)$ & $3.47(.76)$ & $3.53(.64)$ & $3.93(.39)$ \\
Interconnectedness & $3.75(.76)$ & $3.98(.64)$ & $3.98(.54)$ & $3.55(.93)$ & $3.69(.76)$ & $3.80(1.4)$ \\
Religiosity & $3.84(.73)$ & $3.3(.59)$ & $3.08(.5)$ & $3.93(.7)$ & $2.86(.89)$ & $3.08(1.2)$ \\
Paranormal Beliefs & $2.18(.65)$ & $2.34(.59)$ & $2.43(.54)$ & $2.29(.72)$ & $2.22(.65)$ & $3.28(.34)$ \\
Extinction & $3.76(.67)$ & $3.68(.61)$ & $3.72(.47)$ & $3.57(.55)$ & $3.88(.60)$ & $3.08(.47)$ \\
\hline
\end{tabular}

\footnotetext{
*Note. Range of scores for each construct: $1=$ strongly disagree, $3=$ neutral, $5=$ strongly agree.
} 
of common descent (e.g., 1. All species have developed from a common ancestor; 2. Dogs, coyotes and wolves all have a common ancestor). For this measure, the Catholic group scored significantly higher than the Christian Fundamentalist group, who were more likely to disagree with the concept of common descent.

(2) Creationist ( $\alpha=.75, M=3.18, S D=.74)$. The seven items in this measure addressed the belief that God created all living beings and that the universe has not changed since the creation. The bible was not explicitly referenced, so that adherents of any religion could, in theory, endorse the measure (e.g., 1. All living creatures were created by God; 2. Our universe was created by God). For the creationist measure, the Christian Fundamentalist group scored significantly higher than the Catholic group and the Agnostic/No religion group. Only the Catholic and Agnostic groups tended to disagree with creationism.

(3) Adaptation $(\alpha=.77, M=3.55, S D=.63)$. The eight items in this measure focused on the idea that species change over time in response to environmental change (e.g., 1. Species undergo changes as a result of pressure from the environment; 2. If a grass covered island becomes desertlike, some animals might develop the ability to store water (like camels) and they would pass this ability on to their offspring). The Catholic and Christian Non-fundamentalist groups scored significantly higher on this measure than the Christian Fundamentalist group. All religious groups agreed with the adaptation measure.

(4) Interconnectedness $(\alpha=.66, M=3.83, S D=.75)$. The three items in this measure focused on the interconnectivity of species (e.g., 1. If all members of one species migrated to a different area, members of other species left behind would be affected; 2. All species are completely separate from one another, reverse coded). No significant differences for religious group were found for this measure.

(5) Religiosity $(\alpha=.73, M=3.34, S D=.79)$. The five items in this measure addressed a core set of religious beliefs that transcend religious boundaries (e.g., 1. Religion is one way that we can explain things that otherwise have no explanation; 2. Religious writings provide guidelines for correct moral behavior). For this measure, the Christian Fundamentalist and Islamic groups scored significantly higher than the Catholic and 
the Agnostic/No religion groups. The latter, not surprisingly, tended to disagree with the concept of religiosity.

(6) Paranormal Beliefs ( $\alpha=.77, M=2.35, S D=.63$ ). These eight items were intended as a control measure, which focused on beliefs in paranormal phenomena (e.g., 1. Certain individuals can read the thoughts of others; 2. Some people can predict the future). On the paranormal beliefs measure the "Other" religious group scored higher than all other groups except for the Catholic group. In fact, all groups, except for the "Others" disagreed with the measure of paranormal beliefs. The "Other" category consisted of a handful of participants who listed unorthodox religious affiliations (e.g., Pagan, Wicca) or eclectic New Age beliefs (e.g., a mixture of both Western and Eastern religions). We speculate that these participants have an above average tolerance for unconventional beliefs that underlies both an openness to alternative religious practices as well as beliefs in paranormal phenomena. However, it should be noted that this group consisted of only five individuals and therefore caution should be exercised before drawing firm conclusions.

(7) Extinction $(\alpha=.68, M=3.70, S D=.58)$. Eight items that covered participants' general knowledge about extinction were included (e.g., 1. Certain species have become extinct even though humans have never identified them; 2. If an animal's environment is suddenly changed, the entire species might disappear). No significant differences were found for the extinction measure. However, there was one extinction item that was not included in the measure because it addressed the inevitability of extinction, which is a controversial issue, as revealed in a separate study (Poling \& Evans 2004) and as found in the open-ended measure reported earlier. Because the inevitability of extinction is theoretically interesting, we computed a one-way ANOVA on this item ("Extinction is probably the final outcome for all species") across the six religious categories, $F(5,105)=4.71, p<.005$. The Christian Fundamentalists were the only group who disagreed with the concept $(M=2.43, S D=1.2)$. Posthoc comparisons indicated that they were significantly different from the Christian Non-fundamentalists $(M=3.36, S D=.85)$, the Catholics $(M=$ $3.42, S D=.81)$ and the Islamic group $(M=4.0, S D=1.0), p_{\mathrm{s}}<.05$. No other differences were found (Agnostic/No religion $M=3.22, S D=1.1$; Other $M=3.0, S D=1.2$ ). 
In sum, there were consistent differences between religious groups. The Christian Fundamentalist group scored high (more likely to agree) on measures of creationism and religiosity but scored lowest (more likely to disagree) on the common descent and adaptation measures. On the other hand, the Catholic group scored highest on measures of common descent and adaptation, and low on measures of creationism and religiosity. As expected, the agnostic/no religion group scored low on both creationism and religiosity. Like the Christian Fundamentalist group, the Islamic group scored high on the religiosity and creationist measures, and low on the common descent and adaptation measures. Next, correlations between all major measures, education level, and number of biology classes will be reported.

\section{Relationships between Major Constructs}

Major Constructs, Education Level, and Level of Biology Education. In this section we examine the relationships between measures, collapsed across all religious groups. Correlations between all the major measures, educational level, and the number of biology classes completed can be found in Table 5. Significant positive relationships were found between the measure of common descent and measures of adaptation, interconnectedness, paranormal beliefs, education level and number of completed biology classes. In addition positive correlations were found between the measures of adaptation, interconnectedness and extinction and between extinction and interconnectedness.

Significant negative correlations were found between common descent and both the creationist and religiosity measures. However, the measure of creationism, but not the measure of religiosity, was also significantly negatively correlated with the measures of adaptation and extinction indicating that the measures of creationism and religiosity target different underlying concepts. Importantly, there was no relationship between educational level, completed biology classes, and the creationism and religiosity measures.

Regressions on Common Descent and Creationism. Next, separate simultaneous multiple regressions were carried out to assess the differential effects of significantly correlated variables on the common descent and on the creationism measures. Of particular theoretical interest was the independent 
Table 5

Correlations between Seven Constructs of Religious and Species-Related Beliefs

\begin{tabular}{lccccccccc}
\hline Construct & CD & CR & AD & INT & RE & PAR & EX & ED & BIO \\
\hline Common & 1.00 & & & & & & & & \\
Descent (CD) & & & & & & & & & \\
Creationist (CR) & $-.46^{* *}$ & 1.00 & & & & & & & \\
Adaptation (AD) & $.32^{* *}$ & $-.24^{*}$ & 1.00 & & & & & & \\
Interconnect (INT) & $.22^{*}$ & -.07 & $.29^{* *}$ & 1.00 & & & & & \\
Religiosity (RE) & $-.39^{* *}$ & $.68^{* *}$ & -.11 & .05 & 1.00 & & & & \\
Paranormal & $.22^{*}$ & -.04 & .17 & -.09 & -.11 & 1.00 & & & \\
Beliefs (PAR) & & & & & & & & & \\
Extinction (EX) & .14 & $-.19^{*}$ & $.21^{* *}$ & $.35^{* *}$ & .03 & $-.25^{* *}$ & 1.00 & & \\
Education Level (ED) & $.21^{*}$ & -.09 & .07 & $.33^{* *}$ & .02 & -.01 & .07 & 1.00 & \\
\# Biology & $.28^{*}$ & -.16 & .00 & $.21^{* *}$ & .02 & -.06 & .11 & $.49^{* *}$ & 1.00 \\
Courses (BIO) & & & & & & & & & \\
\hline
\end{tabular}

${ }^{*} p<.05,{ }^{* *} p<.01$.

contribution of each variable, partialing out the other effects, as indicated by the standardized regression coefficients $(\beta)$ (Lewis-Beck 1980).

First, creationism, adaptation, interconnectedness, religiosity, paranormal beliefs, education level and number of biology classes were simultaneously regressed on the common descent measure. The combined variables accounted for $37 \%$ of the variance: $R^{2}=.37(R=.61) ; F(7,110)=8.8$, $p<.0001$ (Adjusted $R^{2}=.33$ ). Significant standardized regression coefficients were obtained for adaptation $(\beta=.17, p<.05)$, religiosity $(\beta=-.23, p<.04)$, paranormal beliefs $(\beta=.18, p<.03)$, and biology classes $(\beta=.21, p<.03)$. Creationism approached an alpha level of .05 $(\beta=-.21, p<.07)$. Next, common descent, adaptation, religiosity and extinction were simultaneously regressed on the creationist measure. Overall, the combined variables accounted for $54 \%$ of the variance: $R^{2}=.54$ $(R=.74) ; F(4,110)=31.5, p<.0001$ (Adjusted $\left.R^{2}=.53\right)$, with common descent $(\beta=-.17, p<.03)$, religiosity $(\beta=.61, p<.0001)$ and extinction $(\beta=-.16, p<.02)$ making significant independent contributions.

These results indicate that participants who endorsed common descent had completed more biology classes, were more likely to endorse needbased adaptation and paranormal beliefs, and less likely to be strongly 
religious or creationist. Creationism, on the other hand, was negatively associated with common descent and extinction, but not with adaptation, and strongly positively associated with religiosity.

\section{Adaptation Scenarios}

Each of the three scenarios included in this section described a change in the environment and the effect of that change on a particular species (see Appendix A). Nine randomly ordered items followed each scenario with each item testing a specific concept. Nine measures were created by averaging responses to the similarly worded items across all three scenarios. As before, each item was scaled on a five-point scale $(1=$ strongly disagree; $2=$ disagree, $3=$ neither, $4=$ agree, $5=$ strongly agree), so the range of scores for each concept was 1-5. Results from the four items assessing teleological, intentional, selectional, and theistic modes of species change will be reported. The rest of the items were controls or did not fit within the scope of this paper. The scenarios and items were worded so that they could be used with school-age children in the future, which placed some limits on the way the concepts could be expressed. First, the items will be described and then scores on the four target items will be related to participants' acceptance or rejection of creationism and common descent.

Teleological Change $(M=3.35, S D=.76)$. (All examples are from Scenario 1.) This item measured participants' endorsement of need-based change within a species (e.g., some members of this species are likely to adapt to the pollution and they will survive).

Natural Selection $(M=3.20, S D=.78)$. This item measured participants' endorsement of random variation within a species (e.g., some members of this species will have traits that will protect them from the pollution and they will survive).

Intentional Adaptation $(M=2.80, S D=.72)$. This item measured participants' agreement with the idea that species members could choose to alter their biological functioning (e.g., members of this species can choose to breathe in a different way in order to survive).

God's Intention $(M=3.41, S D=1.16)$. This item measured participants' endorsement of God's plan to intervene and prevent extinction of the species (e.g., members of this species will survive if God wants them to). 
Creationism, Common Descent, and the Adaptation Scenarios. For these analyses, scores on both the common descent and creationist constructs were grouped into three levels of agreement: reject (all scores between 1 and 2.9), neutral agreement (all scores between 3 and 3.5), and accept (all scores between 3.6 and 5). The middle group was excluded from each construct to facilitate direct comparisons between those participants with the highest (accept) and lowest (reject) levels of agreement. ${ }^{2}$ Repeated measures ANOVAs were conducted on the four scenario items with the two-level (accept, reject) common descent and creationist constructs as the independent variables. For both constructs, there was a significant effect of item and an item $\times$ construct interaction $\left(F_{\mathrm{s}}\right.$ from 10.9-30.98, $p_{\mathrm{s}}<.0001$, Greenhouse-Geisser correction used).

Individual t-tests indicated that participants who accepted creationism were significantly more likely to endorse the God's intention item and significantly less likely to endorse the teleology and selection items when compared to participants who rejected creationism (see Table 6, for means, standard deviations, and t-values). There were no significant differences between the accept and reject creationism groups on the intentional adaptation item. An additional ANOVA revealed that participants who accepted creationism had significantly different patterns of responses to the four scenario items, $F(3,87)=20.87, p<.0001$ (Greenhouse-Geisser correction used). They were least likely to accept the intentional adaptation item and most likely to accept the role of God's intention (Bonferroni posthoc tests: all $\left.p_{\mathrm{s}}<.008\right)$. But, it should be noted that they tended to agree with the teleological change item. Participants who rejected creationism also had significantly different levels of agreement on the four scenario items, $F(3,102)=21.53, p<.0001$ (Greenhouse-Geisser correction used). They were more likely to agree with teleological change and natural selection than with either of the other items $\left(p_{\mathrm{s}}<.001\right)$.

\footnotetext{
${ }^{2}$ For creationism, $31.5 \%$ of participants were classified as rejecting creationism, $41.4 \%$ were neutral and $27 \%$ accepted creationism. For common descent, $30.6 \%$ rejected common descent, $40.5 \%$ were neutral and $28.8 \%$ of participants accepted common descent. In addition, $29.7 \%$ of participants had high agreement on one measure and low agreement on the other (i.e., consistently responding along creationist lines or evolutionary lines): Consistent creationists $(n=15)$, Consistent Evolutionists $(n=18)$. A further $70.2 \%$ of participants were either neutral on both measures or had mixed (inconsistent) levels of agreement across the two measures.
} 
Table 6

Mean Responses of the Accept and Reject Creationism Groups on Four Items from the Adaptation Scenarios

\begin{tabular}{lccc}
\hline Adaptation Items & \multicolumn{3}{c}{ Creationist Groups } \\
\cline { 2 - 4 } & $\begin{array}{c}\text { Accept Group } \\
\text { Mean (SD) } \\
n=35\end{array}$ & $\begin{array}{c}\text { Reject Group } \\
\text { Mean (SD) } \\
n=30\end{array}$ & t-value \\
\hline Teleological Change & $3.2(.84)$ & $3.6(.72)$ & $2.1^{*}$ \\
Natural Selection & $3.0(.88)$ & $3.5(.65)$ & $2.6^{* *}$ \\
Intentional Adaptation & $2.6(.66)$ & $2.8(.78)$ & 1.0 \\
God's Intention & $4.1(.89)$ & $2.5(.94)$ & $-7.1^{* * *}$ \\
\hline
\end{tabular}

${ }^{*} p<.05,{ }^{* *} p<.01,{ }^{* * *} p<.0001$.

Note. Range of scores for each construct: $1=$ strongly disagree, $3=$ neutral, $5=$ strongly agree.

Although, participants who accepted or rejected the common descent measure differentially endorsed the God's Intention item in the expected direction, they did not differ significantly on the other items, although the trend was in the expected direction. Overall, these results suggested that the measure of common descent was less sensitive to differences between participants than was the measure of creationism. The common descent measure had been deliberately constructed so that some items included species that were highly similar, whereas other items included dissimilar, more diverse species. Based on the extant research on diversity reasoning (e.g., Lo, Sides, Rozelle \& Osherson 2002) we examined the items to determine whether participants differed in their responses to the similar and dissimilar constructs. As can be seen in Appendix B (for means \& $\mathrm{SDs})$ there were clear differences. Overall, participants were likely to agree that highly similar groups of species had a common ancestor, and disagree with the idea that dissimilar species had a common ancestor. In the final analyses we investigated whether these differences were maintained within the evolutionist and creationist groups, using the three-level creationism measure as a proxy for these groups.

Creationism, Common Descent and Diversity Reasoning. Theoretically, creationists (accept creationism group) should argue that no species pairs have a common ancestor, and evolutionists (reject creationism group) should argue that all species have a common ancestor. They should not deviate from 


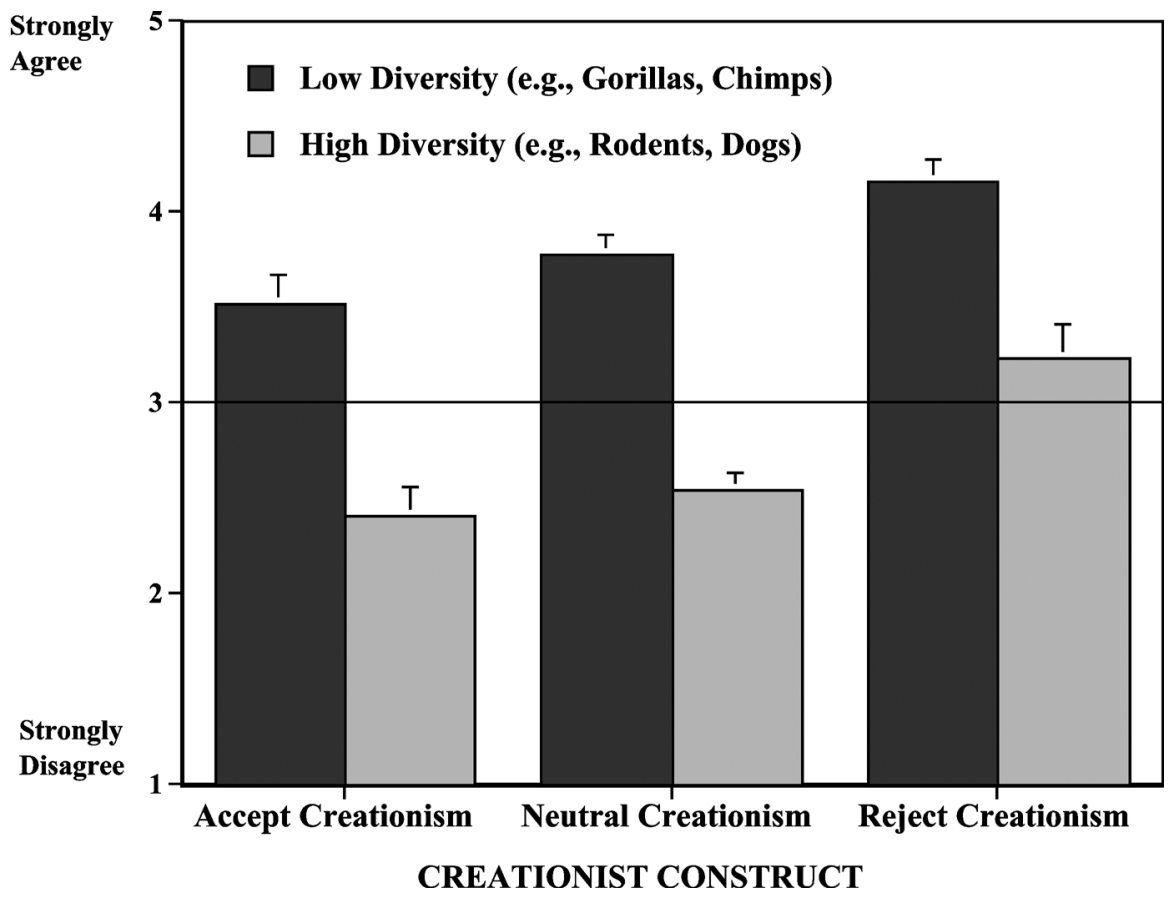

Figure 2. Agreement with common ancestry for diverse and non-diverse species groups as a function of creationist belief (mean agreement, SE).

these arguments depending on the similarity of the species. Items from the common descent measure were used as a gauge of diversity reasoning in this sample. Each item in the common descent measure required participants to reason about the possibility of a shared ancestry between two or more species. The four items containing the highest level of similarity (low diversity) between species and the four items containing the lowest level of similarity (high diversity) between species were used to create two new variables (see Appendix B for items).

This measure of diversity (High, Low) reasoning was analyzed in a repeated measures ANOVA with the accept, neutral, and reject creationism groups (see Figure 2 for means and standard errors). There was a significant main effect for diversity reasoning, $F(1,108)=237.79, p<.0001$ and for creationism, $F(2,108)=11.39, p<.0001$, and no interaction. All three creationist groups (accept, neutral and reject) were more likely to agree that similar (low diversity) species shared a common ancestor, when 


\section{Table 7}

Mean Agreement (and Standard Deviations) on Two General Common Descent Items for Three Groups of Creationism Acceptance

\begin{tabular}{lcc}
\hline Greationism Groups & \multicolumn{2}{c}{ Items } \\
\cline { 2 - 3 } & $\begin{array}{c}\text { All species have a } \\
\text { common ancestor }\end{array}$ & $\begin{array}{c}\text { No species share a } \\
\text { common ancestor }\end{array}$ \\
\hline Accept Creationism & $2.4(1.4)$ & $2.3(1.03)$ \\
Neutral Creationist & $2.8(1.1)$ & $2.1(.80)$ \\
Reject Creationism & $3.3(1.2)$ & $1.8(.88)$ \\
\hline
\end{tabular}

Note. Range of scores for each item: $1=$ strongly disagree, $3=$ neutral, $5=$ strongly agree.

compared with the dissimilar (high diversity) species (all $p_{\mathrm{s}}<.0001$ ). Furthermore, as expected, overall, participants who rejected creationism were more likely to endorse common descent than were the neutral or accept creationism groups, on both the high diversity and low diversity variables $\left(p_{\mathrm{s}}<.05\right.$; see Figure 2). A similar set of analyses was also performed using the consistency measure described earlier (see Note 2). The same pattern of results was obtained, with significant differences between the high and low diversity measures for both the consistent creationists and the consistent evolutionists.

Finally, we examined two items that were included in the common descent construct, but were not included in the diversity reasoning analyses because they did not require comparisons between specific species (see Table 7 for means and standard deviations): All species have developed from one common ancestor, and there are no species that share a common ancestor (this was reverse coded in the original construct, but not in this analysis). A repeated measures analysis on these items by accept, neutral and reject creationism groups revealed a significant main effect of item $F(1,108)=22.58, p<.0001$, and an item by creationist interaction $F(2,108)=6.44, p<.005$. Although no groups agreed strongly with either of these items, Bonferroni comparisons revealed that participants who rejected creationism had higher levels of disagreement for the "no species" item when compared to those who accepted or were neutral on creationism, and participants who accepted creationism had more disagreement on the "all species" item compared to the reject and neutral 
groups $\left(p_{\mathrm{s}}<.05\right)$. Again, similar analyses on the consistent creationists and evolutionists (see Note 2) revealed the same effect.

\section{Discussion}

Overall, these analyses suggest that in the lay population, folk concepts of species and species change survive the impact of Darwinian and creationist cultural models. Nonetheless, they do not survive intact. Neither creationists nor evolutionists respond in a manner that is consistent with an hypothesis of a radical transformation of their commonsense species concepts. Instead, the evidence suggests that their folk ecology is substantially modified, with a concept of species playing a major role in the way it is modified. We summarize the key findings and in the process we address the questions raised earlier about the influence of religion and science on lay-adults' folk ecology. Then we briefly consider the implications of these findings for folk concepts of species and the relationship of these constructs to the practice of science itself.

The Influence of Religion and Science on Lay-Adults' Folk Ecology. Analyses of the beliefs of diverse religious groups, equated for educational level, found Christian Fundamentalist and Islamic participants to be both more strongly religious and more strongly creationist than the other groups (see Table 4). Furthermore, unlike the other groups, the Christian fundamentalists rejected the macroevolutionary concept of common descent, and the Islamic group was neutral towards it. Nevertheless, both groups endorsed the folk concept of need-based adaptation within species, albeit at much lower levels than other religious groups in the study. Such results confirm earlier findings for these religious groups (e.g., Dagher \& BouJaoude 1997; Evans 2001), and, moreover, they provide evidence that macroevolutionary and microevolutionary constructs are conceptualized as dissimilar by a lay-population (see Figure 1). Notably, the Catholics in this study endorsed macro- and microevolutionary measures at significantly higher levels than the other religious groups, and also rejected creationism. As mentioned earlier, creationist beliefs can be found in a variety of religious groups, thus in the rest of the analyses measures were collapsed across religious groups, resulting in more sensitive instruments.

Participants who accepted the Darwinian theory of common descent had taken more biology classes and were more sensitive to ecological issues, 
including the responsiveness of species to environmental change (adaptive variation) and the extinction of species (see Table 5). Biology education apparently increases knowledge of common descent, however, it is also possible that there is a selection effect, in that creationists are not likely to enroll in biology classes. Agreement with the theory of common descent was negatively associated with creationism and religiosity, independently of each other. An interesting positive association between common descent and paranormal beliefs may represent an openness to unusual ideas (e.g., see Sinatra et al. 2003). Strong creationists, on the other hand, rejected extinction and common descent, but not adaptive variation, confirming that macro- rather than micro-evolutionary constructs are more likely to be incompatible with creationism. Although participants who were strongly creationist were also highly religious, these two measures appeared to be independent constructs. Unlike creationism, religiosity was unrelated to any measure other than common descent. Importantly, the educational level of the participants bore no independent relationship to the other measures, though, not surprisingly, participants who had taken more biology classes tended to have more years of education.

This sample appeared to be representative of the U.S. population, as described in the introduction, in that approximately a third of the participants agreed strongly with creationist ideas (Doyle 2003). Intriguingly, detailed analyses of the creationism and common descent constructs revealed that a significant number of participants endorsed both beliefs, in a variety of combinations. This mixed response pattern is consistent with earlier studies (Brem et al. 2003; Evans 2000a, 2001) indicating that single item measures, such as those reported in Gallup polls, rarely convey the complexity of the reasoning patterns of the lay adult (Evans 2000b). This variability, however, made it possible to analyze the effects of the strength of individuals' beliefs, instead of the absence or presence of these beliefs. It also provides evidence that the piecemeal assimilation of cultural belief systems has a cumulative rather than an all-or-nothing effect.

For microevolutionary constructs, the differences between evolutionists and creationists tended to be one of degree, whereas for macroevolutionary constructs, the differences were more profound. Evolutionists agreed with macroevolutionary constructs, such as common descent and extinction, whereas creationists disagreed with them. All participants agreed with 
adaptive variation (adaptation), a microevolutionary construct, but evolutionists had higher levels of agreement than did the creationists.

Responses to the adaptation scenarios were especially instructive (see Table 6). Participants were divided into three groups depending on whether they accepted, were neutral towards, or rejected creationist beliefs. They rated their degree of agreement to four explanations for species change. All participants disagreed with the intentional explanation (animals can choose to change) but agreed with the teleological explanation (animals adapt to changed environments) providing further evidence that these two constructs are dissociable. However, those who rejected creationism (evolutionists) were much more likely than those who accepted creationism to strongly endorse the teleological and the selectionist explanations and reject the theistic (God's plan) explanation; whereas, the reverse pattern was found for the accept-creationism group. This entire pattern of results suggests that creationist and evolutionist lay-adults both retain their folk concept of needbased adaptive change within species, with some modifications. When it comes to macroevolutionary constructs, however, creationists consider God to be the source of new species and species change, whereas evolutionists endorse naturalistic explanations of species origins and change.

A more detailed examination of the common descent measure complicated this picture. Some form of similarity reasoning apparently constrained all participants' responses, regardless of prior belief system. Normally, in the diversity effect, participants draw stronger conclusions when diverse or dissimilar exemplars are used in the argument (e.g., Heit \& Hahn 2001; Lo, Sides, Rozelle \& Osherson 2002). This study employed a different procedure, in which the extent to which participants agreed that species $\mathrm{X}$ and species $\mathrm{Y}$ had a common ancestor, was examined. Theoretically, creationists should agree that no species pairs have a common ancestor, whereas evolutionists should agree that all species have a common ancestor (see Table 7). The similarity of species X to species Y should not affect this conclusion.

A serendipitous finding indicated that regardless of prior belief system, the more similar the species, the more likely were participants to agree that species pairs had a common ancestor. The accept- and neutralcreationist groups agreed that similar species had a common ancestor, though they considered dissimilar species unlikely to have a common 
ancestor (see Figure 2). Overall, as expected, evolutionists were more likely than creationists to accept the idea of common descent, whether or not the species were dissimilar. Finally, the statement, "No species have a common ancestor," should elicit a high level of agreement from creationists, and a high level of disagreement from evolutionists. Yet, all participants disagreed with the statement, with evolutionists disagreeing more strongly. A partial explanation for this set of findings, we shall argue, must lie in lay adults' concepts of species. Similar species, such as gorillas and chimpanzees or dogs and wolves are apparently considered to be the same "kind" raising the possibility that an ancestor is just another version of the same kind, not a distinct species. Dissimilar species, in contrast, may well be considered different kinds, therefore lay adults reason that they are unlikely to share a common ancestor.

More strikingly, these results reveal that lay-evolutionists (as opposed to evolutionary biologists) do not strongly endorse macroevolutionary concepts, wherein all species, including the human, have a common ancestor. On the other hand, neither do lay-creationists (as opposed to creation scientists) strongly endorse Biblical literalism, in which each species has an unique immutable God-given essence. These results can be augmented by the account given by Medin and Atran (in press) of the biological concepts of North American undergraduates. Their studies indicated that in comparison with groups from the same or different cultures who had more biological knowledge, North American undergraduates were more likely to engage in diversity reasoning and more likely to privilege the life-form level when reasoning. It is possible that either or both effects are being observed in this diversity reasoning condition; further studies are needed to disentangle these effects. Such studies should be extended to include participants who are reasoning about actual biological kinds. A limitation of this method is a reliance on paper and pencil tests of participants' agreement (or not) with a series of written propositions.

Species Concepts in Industrialized Societies. Only 7\% of the lay adults in this study included reproductive isolation or a common ancestry in their definition of species. The majority defined a species as a group of animals "like mice or humans." This is close to a pre-Darwinian concept, though only $5 \%$ explicitly referred to God. This evidence, when integrated with 
the above findings, indicates that it would be a mistake to assume that lay-adults in contemporary societies who endorse evolution have a postDarwinian view of species, even if they reject creationist ideas. Their understanding appears to be more of a synthetic blend, comprising a commonsense awareness of generic-species intertwined with partially assimilated evolutionary concepts (Atran 1990; Evans \& Rosengren 2004; Vosniadou $\&$ Brewer 1987). The lay-adult appears to adopt a pre-Darwinian view of evolution, in which species adapt to novel environmental conditions, but, remain, in effect, the same kind despite the changes (see Atran 1990). This adaptationist view yields interesting consequences: Unlike expert biologists, adaptationists do not agree that species extinction is probable and they are especially likely to reject the idea that humans could become extinct (Poling \& Evans 2004).

The concepts of species found in contemporary industrialized societies apparently include an explicit Biblical literalist concept, implicit preDarwinian adaptationist concepts, and an explicit post-Darwinian evolutionist concept (see Figure 1). Only the latter offers a viable naturalistic account of the emergence of distinct new species. The difference between these accounts centers on beliefs about: (1) the nature of a species (2) the relationship between species and (3) the responsiveness of species to environmental change (see Figure 1). For Biblical literalists each species is individually created by God, thus the idea of a common descent is anathema. Although creation scientists (and young children) accept that species have environmental niches to which they are uniquely adapted, called static adaptation (Evans 2000a), they do not agree that species may change in response to novel environments because this is incompatible with an essentialist view of species as stable and unchanging. Adaptationists and Darwinian evolutionists, on the other hand, acknowledge the role of novel environments in species change. For Darwinians, but not necessarily for the adaptationists, if the environment changes sufficiently then distinct new species might emerge and the parent species might become extinct. According to Darwinians, for example, a geographic separation of the original population could lead to genetic divergence and a failure to interbreed, thus, if sufficient numbers survive, a new species emerges.

Although, 69\% of the lay adults in this study thought that extinction referenced the death of a species, if they do not have a post-Darwinian 
concept of species then it is unclear what they make of extinction. In this and an earlier study, most lay adults rejected the idea that extinction was inevitable, though evolutionary biologists overwhelmingly endorse the nearinevitability of extinction (Poling \& Evans 2004). Lay-adults in this study who were strongly creationist were especially likely to deny the possibility of extinction, ascribing the survivability of species to God's plan. For lay adults who characterize species to be kinds that adapt to new environments, a similar species, even if it could not interbreed with the original one, would still be the same kind (Evans \& Rosengren 2004). Thus, the ancestor population would not be considered extinct.

How might folk beliefs and religious beliefs constrain scientific practice? Although, in this study, we did not specifically consider how practitioners of science reconcile their folk beliefs or religious convictions with their professional roles, the results can be instructive in understanding the practice of science itself. The lay-adults in this study consisted of individuals working toward college degrees, some of whom will presumably be practicing science in the future. Anecdotal evidence, described earlier, suggests that when scientific expertise contradicts ingrained religious beliefs this may create enough dissonance for the scientific field to be abandoned all together (e.g., Alfred H. Meyer as cited in Numbers 1992). Most individuals, however, self-select areas of expertise that do not seriously challenge their preexisting belief systems. Many fields, even within the biological sciences, offer a wide variety of niches, some of which may be compatible with a creationist worldview (Numbers 1992). Further, there are many scientific or mathematical fields, such as engineering or business, which offer no challenge whatsoever, and which attract creationists (Cavanaugh 1985). As described earlier, a generic education in biology is not enough to shift core folk beliefs about species and extinction. Only concentrated expertise in the specialized fields of evolutionary biology and ecology underlie scientifically sophisticated species concepts (Poling \& Evans 2004).

In a related study, which focused on concepts of death and extinction, Poling and Evans (2004) examined the beliefs of children, lay-adults, medical students, and evolutionary biologists from an ecology and evolutionary biology concentration at a Midwestern university. Evolutionary biologists were more likely to view all species as interrelated, a belief that was tied to the acknowledgement that extinction is an inevitable and necessary com- 
ponent of evolution (see Figure 1). In addition, evolutionary biologists were more likely to eschew spiritual or religious explanations for what happens after death. Instead, they gave responses that were more biologically based, including decomposition and the subsequent use of organic matter by other living organisms. Further, the evolutionary biologists were less likely than the other groups to have religious affiliations. Those biologists who did have a religious affiliation, though, were less likely to acknowledge that extinction is inevitable when compared with their non-religious peers (Poling \& Evans 2004). Such findings support the speculation that individuals with strong religious beliefs may be less likely to choose a science that contradicts these beliefs. In addition, they suggest that biological expertise involves the transformation of folk ecological beliefs. Further research along these lines should use a developmental or microgenetic approach, to establish exactly how such a transformation is accomplished in an expert population.

\section{Conclusion}

Contemporary lay-adults' folk beliefs resemble those of early-stage naturalists (Atran 1990). Even lay-creationists resist the hyper-essentialism of the Biblical literalists, in that they tend to accept within-species variation due to need-based adaptation to the environment. Moreover, lay-evolutionists resist the concept of speciation due to random variation and selection processes, the Darwinian model. Lay adults are apparently susceptible to rule-based, explicit cultural models emerging from science or religion. Yet, cultural models appear to modify but not override lay-adults' implicit, teleo-essentialist, concepts of species and species change, which are further constrained by similarity-based reasoning (see Figure 2). This could also be the case for evolutionary biologists and creation scientists, who may revert to a folk biology at an implicit level, only demonstrating the rule-based reasoning of their respective endeavors when assessed using techniques that access their explicit knowledge of the topic. We argue instead, however, that with repeated exposure to domain specific knowledge, experts view the natural world through a different lens, with their basic causal construals transformed but not eliminated by cultural input. How might this occur?

We adopt a position similar to that expressed by Keil (1994), which is that to explain animate behavior all three modes of construal, intention, essentialism, and teleology are needed. It is the particular combination that 
delivers a particular explanation (Poling \& Evans 2002; Evans \& Rosengren 2004). Further, as described earlier, such a mix would explain shifts in reasoning across cultures and historical and developmental time. These findings and those from our earlier studies (Evans 2000a, 2001; Poling \& Evans 2002, 2004) support Keil's position that none of these explanatory modes are uniquely tied to a domain ... they act as "footholds" that foster the acquisition of more "elaborated belief systems in . . . a number of specialized domains" (1994, p. 251).

Teleological explanation or goal-directed behavior is of key importance as it can be construed as an adaptive response to the environment. Adaptation to the current environment can occur via an anticipatory mental state, a teleo-intentional explanation, which is the core of a folk-psychological explanation. A teleo-essentialist explanation would be realized as an adaptation to ancestral environments via genetic or unanalyzed internal structures, the core of a folk-biological explanation (Evans \& Poling 2003). A constrained causal flexibility with shifts between different modes of construal would occur as more knowledge is acquired, which fleshes out the skeletal structures of particular domains. As individuals immerse themselves in the evidence provided by their communities their explanatory stances shift from a commonsense folk biology to those of their respective belief systems (see Figure 1). Biblical literalists insist on the primacy of God's word as revealed in the Bible, whereas evolutionists rely on the evidence provided by nature, alone. Atran (1998) argues that "functionally unhinged" causal principles "independent of the stimulus domains to which they eventually apply, seem implausible from an evolutionary standpoint" (p. 596). We do not suggest, however, that such principles are independent of the animate domain, but just that they do not necessarily deliver a folkbiology module with essentialism as a core construct (see Gelman 2003). Further research on the conceptual primitives underlying the emergence of knowledge structures is necessary to disentangle these issues (e.g., Mandler 2000).

Science instruction that explicitly targets students' naive epistemology, as described earlier, as well as encouraging a metacognitive awareness of implicit folk concepts, is likely to have a much greater chance of successfully producing an educated lay-population and a new generation of scientists. Scientists, it would appear, have to consciously and repeatedly 
apply the constructs of their disciplines, such as a post-Darwinian definition of species, in order to transcend their common-sense folk beliefs.

\section{Appendix A: Adaptation Scenarios}

1. All members of a certain species "X" had a special breathing passage that made the air go into their bodies. There was an explosion in space and it caused the air on earth to be polluted. No other animals were affected by the pollution. However, for species X, the pollution in the air destroyed the special breathing passage.

2. A certain species "Y" has a thick coat of fur and cannot live in temperatures above $50^{\circ}$. Global changes in climate made the environment too warm for species $\mathrm{Y}$ to live. No other animals were affected by the warm weather. However, species $\mathrm{Y}$ does not shed the thick fur coat and there is no environment that remains below $50^{\circ}$.

3. Members of a species "Z" eat special types of plants in order to stay alive. All the plants that this species eats have disappeared because of pollution in the rain. No other animals need these plants to survive but now there is no more food left for species $\mathrm{Z}$ to eat.

\section{Appendix B: Mean Agreement Scores (Standard Deviations) for the Whole Sample on Items Used to Test Diversity Reasoning}

Mean (S.D.)

Low Diversity/High Similarity

Gorillas, monkeys, and chimpanzees all have a common ancestor

Salamanders, lizards and crocodiles have a common ancestor

Dogs, coyotes and wolves all have a common ancestor

Monkeys, baboons, and humans all have a common ancestor

$3.38(1.3)$

High Diversity/Low Similarity

Crocodiles, rodents and turtles all have a common ancestor

Rodents and dogs have a common ancestor

Rats, whales, and zebras all have a common ancestor

Dolphins and humans have a common ancestor

$2.43(1.2)$

Note. Range of scores for each construct: $1=$ strongly disagree, $3=$ neutral, $5=$ strongly agree. 


\section{REFERENCES}

\section{Allen, G., M. Bekoff \& G. Lauder}

1998 "Introduction." In C. Allen, M. Bekoff \& G. Lauder (Eds.), Nature's purposes: Analysis of function and design in biology (pp. 1-27). Cambridge, MA: MIT Press.

Anderson, O.R., D. Randle \& T. Govotsos

2001 The role of ideational networks in laboratory inquiry learning and knowledge of evolution among seventh grade students. Science Education 85, 410-425.

Atran, S.

1990 Cognitive foundations of natural history: Towards an anthropology of science. Cambridge: Cambridge University Press.

1995 "Causal constraints on categories and categorical constraints on biological reasoning across cultures." In D. Sperber, D. Premack \& A.J. Premack (Eds.). Causal cognition: A multidisciplinary debate (pp. 205-233). Oxford: Clarendon Press.

1998 Folk Biology and the anthropology of science: Cognitive universals and cultural particulars. Behavioral and Brain Sciences 21, 547-609.

Atran, S., D. Medin \& N. Ross

2004 Evolution and devolution of knowledge: A tale of two biologies. Fournal of the Royal Anthropological Institute 10, 395-420.

BANET, E. \& G.E. AYUSO

2003 Teaching of biological inheritance and evolution of living beings in secondary school. International Fournal of Science Education 25, 373-407.

BelL, R.L., N.G. LEDERMAN \& F. ABD-El-Khalick

2000 Developing and acting upon one's conception of the nature of science: A followup study. Fournal of Research in Science Teaching 37, 563-581.

BISHOP, B.A. \& G.W. ANDERSON

1990 Student conceptions of natural selection and its role in evolution. Fournal of Research in Science Teaching 27, 415-428.

BizzO, N.M.V.

1994 From down house landlord to Brazilian high school students: What has happened to evolutionary knowledge on the way. Fournal of Research in Science Teaching $31,537-556$.

BRem, S.K., M. RANney \& J. Sahindel

2003 Perceived consequences of evolution: College students perceive negative personal and social impact in evolutionary theory. Science Education 87, 181-206.

BRUMBY, M.N.

1979 Problems in learning the concept of natural selection. Fournal of Biological Education 13, 119-122.

1984 Misconceptions about the concept of natural selection by medical biology students. Science Education 68(4), 493-503.

Carey, S.

1985 Conceptual change in childhood. Cambridge. MA: MIT Press.

1995 "On the origins of causal understanding." In D. Sperber, D. Premack \& A.J. Premack (Eds.), Causal cognition: A multidisciplinary debate (pp. 268-302). Oxford: Clarendon Press. 
Chambers, R.

1994 Vestiges of the Natural History of Creation and Other Evolutionary Writings (Originally published in 1844 and 1845). Chicago and London: The University of Chicago Press.

CHIGK, J.T.

2000 English-Big Daddy. http://www.chick.com/reading/tracts/0055/0055 01.asp

Clough, E.E. \& C. Wood-Robinson

1985 How secondary students interpret instances of biological adaptation. Fournal of Biological Education 19, 125-130.

Cobern, W.W.

2000 The nature of science and the role of knowledge and belief. Science and Education 9, 219-246.

Cohen, J.

1960 A coefficient of agreement for nominal scales. Educational and Psychological Measurement 20, 37-46.

Crews, F.

2001 Saving us from Darwin. The New Tork Review of Books. XLVIII: 24-27.

Cavanaugh, M.A.

1985 Scientific creationism and rationality. Nature 315, 185-189.

DAGHER, Z.R. \& S. BOUJAOUdE

1997 Scientific views and religious beliefs of college students: The case of biological evolution. Fournal of Research in Science Teaching 34, 429-445.

DAWKINS, R.

1987 The Blind Watchmaker. New York: Norton.

DeAdman, J.A. \& P.J. Kelly

1978 What do secondary school boys understand about evolution and heredity before they are taught about the topics. Fournal of Biological Education 12, 7-15.

DOYLE, R.

2003 Sizing up evangelicals: Fundamentalism persists but shows signs of moderation. Scientific American 228, 37.

Evans, E.M.

2000a The emergence of beliefs about the origins of species in school-age children. Merrill-Palmer Quarterly 46(2), 221-254.

2000b "Beyond Scopes: Why creationism is here to stay." In K. Rosengren, C. Johnson and P. Harris (Eds.), Imagining the impossible: Magical, scientific, and religious thinking in children (pp. 305-331). Cambridge, UK: Cambridge University Press.

2001 Cognitive and contextual factors in the emergence of diverse belief systems: Creation versus evolution. Cognitive Psychology 42, 217-266.

Evans, E.M. \& D.A. Poling

2003 Causal flexibility in children's and adults' reasoning about living kinds. In E.M. Evans, \& G. Hatano, (Co-Chairs), How do children reason about nature? Biennial Meeting of the Cognitive Development Society, Park City, UT, October. 
Evans, E.M., D.A. Poling \& M.S. Mull

2001 Confronting the existential questions: Children's understanding of death and origins. Paper presented at the Biennial Meeting of the Society for Research In Child Development, Minneapolis, MN, April.

Evans, E.M. \& K.R. Rosengren

2004 Why is evolution so difficult to "think"? A developmental constraints perspective. Unpublished manuscript.

Ferrari, M. \& M.T.H. CHI

1998 The nature of naive explanations of natural selection. International fournal of Science Education 20(10), 1231-1256.

GeLman, S.A.

2003 The Essential Child: Origins of Essentialism in Everyday Thought. Oxford: Oxford University Press.

GeLman, S.A. \& H.M. WelLman

1991 Insides and essences: Early understandings of the non-obvious. Cognition 38, 213244.

Gutheil, G., A. Vera \& F.C. Keil

1998 Do houseflies think? Patterns of induction and biological beliefs in development. Cognition 66, 33-49.

Hatano, G., K. InAGaki \& E. Morita

2002 "Understanding of adaptation and evolution by elementary school children." In G. Hatano, (Chair), The evolution of the evolution concept: Effects of intervention. Paper presented at the Annual Meeting of the American Education Research Association, New Orleans, LA, April.

HeIt, E. \& U. HAHN

2001 Diversity-based reasoning in children. Cognitive Psychology 43, 243-273.

INAGAKI, K. \& G. HATANO

2002 Young children's naive thinking about the biological world. New York: Psychology Press.

JEFFREY, K.R. \& L.E. ROACH

1994 A study of the presence of evolutionary protoconcepts in pre-high school textbooks. Fournal of Research in Science Teaching 31, 507-518.

Johnson-laird, P.N., P. Legrenzi \& V. Girotto

2004 How we detect logical inconsistencies. Current Directions in Psychological Science 13, 41-45.

KEIL, F.C.

1994 "The birth and nurturance of concepts by domains: The origins of concepts of living things." In L.A. Hirschfeld and S.A. Gelman (Eds.), Mapping the mind: Domain specificity in cognition and culture (pp. 234-254). Cambridge: CUP.

KEIL, F.C. \& R.A. WILsON

2000 "Explaining explanation." In F.C. Keil and R.A. Wilson (Eds.), Explanation and cognition (pp. 1-19). Cambridge, MA: The MIT Press.

Kelemen, D.

1999 The scope of teleological thinking in preschool children. Cognition 70, 241-272. 
2004 Are children "intuitive theists"? Reasoning about purpose and design in nature. Psychological Science 15, 295-301.

LAWSON, A.E. \& W.A. WORSNOP

1992 Learning about evolution and rejecting a belief in special creation: Effects of reflective reasoning skill, prior knowledge, prior belief and religious commitment. Journal of Research in Science Teaching 29, 143-166.

LEWIS-BECK, M.S.

1980 Applied regression. Beverly Hills, CA: Sage.

Lo, Y., A. Sides, J. Rozelle \& D. Osherson

2002 Evidential diversity and premise probability in young children's inductive judgment. Cognitive Science 26, 181-206.

MANDLER, J.M.

2000 Perceptual and conceptual processes in infancy. Fournal of cognition and development 1, 3-36.

MAYR, E.

1982 The growth of biological thought: Diversity, evolution and inheritance. Cambridge, MA: Harvard University Press.

1991 One long argument: Charles Darwin and the genesis of modern evolutionary thought. Cambridge, MA: Harvard University Press.

MEDin, D.L. \& S. ATRAN

(in press) The native mind: Biological categorization and reasoning in development and across cultures. Psychological Review.

Medin, D. \& A. Ortony

1989 "Comments on Part 1: Psychological essentialism." In S. Vosniadou and A. Ortony (Eds.), Similarity and analogical reasoning (pp. 179-193). Cambridge, US: Cambridge University Press.

Mishler, B.D.

1999 "Getting rid of species?" In R.A. Wilson (Ed.), Species: New Interdisciplinary essays (pp. 307-315). Cambridge, MA: MIT Press.

Morris, H.M. \& G.E. PArker

1982 What is creation science. El Cajon, CA: Master Books.

Numbers, R.L.

1992 The creationists: The evolution of scientific creationism. New York: Knopf.

OPFER, J.E.

2002 Identifying living and sentient kinds from dynamic information: the case of goaldirected versus aimless autonomous movement in conceptual change. Cognition 86, 97-122.

PAssmore, C. \& J. Stewart

2002 A modeling approach to teaching evolutionary biology in high schools. Fournal of Research in Science Teaching 39, 185-204.

PENNOCK, R.T.

2002 Should creationism be taught in the public schools? Science and Education 11, 111-133. 
Poling, D.A. \& E.M. Evans

2002 Why do birds of a feather flock together? Developmental change in the use of multiple explanations: Intention, teleology, essentialism. British fournal of Developmental Psychology 20, 89-112.

(2004) Are dinosaurs the rule or the exception? Developing concepts of death and extinction. Cognitive Development 19, 363-383.

Rosengren, K.S., G. Dehart, M.G. Taylor \& D.P. Marzolf

2003 Kittens \& cats, caterpillars \& butterflies: Children's understanding of parentoffspring resemblance. Manuscript under review.

Rosengren, K.S., S.A. Gelman, C. Kalish \& M. Macormick

1991 As time goes by: Children's early understanding of growth in animals. Child Development 62, 1302-1320.

Ross, N., D. Medin, J. Coley \& S. Atran

2003 Cultural and experiential differences in the development of folk biological induction. Cognitive Development 18, 25-47.

SAMARAPUngaVAn, A. \& R.W. Wiers

1997 Children's thoughts on the origin of species: A study of explanatory coherence. Cognitive Science 21, 147-177.

SANDOVAL, W.A. \& K. MORRISON

2003 High school students' ideas about theories and theory change after a biological inquiry unit. Fournal of Research in Science Teaching 40, 369-392.

SECORD, J.A.

1994 Introduction. Vestiges of the Natural History of Creation and Other Evolutionary Writings. Chicago and London: The University of Chicago Press.

Settlage JR., J.

1994 Conceptions of natural selection: A snapshot of the sense-making process. Fournal of Research in Science Teaching 31, 449-457.

Shtulman, A.

2003 Intuitive evolution: The role of conceptual change in learning Darwinism. Paper presented at the Biennial meeting of the Society for Research in Child Development, Tampa, FL, April.

Sinatra, G.M., S.A. Southerland, F. Mcconaughy \& J.W. Demastes

2003 Intentions and beliefs in students' understanding and acceptance of biological evolution. Fournal of Research in Science Teaching 40(5), 510-528.

Southerland, S.A., E. Abrams, G.L. Cummins \& J. Anzelmo

2001 Understanding students' explanations of biological phenomena: Conceptual frameworks or P-Prims. Science Education 85, 328-348.

SPRINGER, K. \& F.C. KEIL

1989 On the development of biologically specific beliefs: The case of inheritance. Child Development 60, 637-648.

Swarts, F.A., O.R. Anderson \& F.J. SwEtz

1994 Evolution in secondary school textbooks of the PRC, the USA, and the latter stages of the USSR. Fournal of Research in Science Teaching 31, 475-505. 
Trowbridge, J.E. \& J.H. WANDERsee

1994 Identifying critical junctures in learning in a college course on evolution. Zournal of Research in Science Teaching 31, 459-473.

TVERsky, A. \& D. KAHNEMAN

1974 Judgment under uncertainty: Heuristics and biases. Science 185, 1124-1131.

VOSNIADOU, S. \& W.F. BREWER

1987 Mental models of the earth: A study of conceptual change in childhood. Cognitive Psychology 51, 51-67.

Vosniadou, S. \& C. IOANnides

1998 From conceptual development to science education: a psychological point of view. International Fournal of Science Education 20, 1213-1231.

Wandersee, J.H., J.J. Mintzes \& M.W. ARnAUdin

1987 "Children's biology: A content analysis of conceptual development in the life sciences." In J.D. Novak (Ed.), Proceeding of the Second International Seminar on Misconceptions and Educational Strategies in Science and Mathematics. Ithaca, NY: Cornell University.

Wellman, H.M. \& S.A. Gelman

1998 "Knowledge acquisition in foundational domains." In W. Damon, D. Kuhn and R. Siegler (Eds.), Handbook of Child Psychology: Vol. 2. Cognition, Perception and Language (pp. 523-574). New York: Wiley. 